\title{
Comparison of UV irradiance measurements at Summit, Greenland; Barrow, Alaska; and South Pole, Antarctica
}

\author{
G. Bernhard, C. R. Booth, and J. C. Ehramjian \\ Biospherical Instruments, San Diego, USA \\ Received: 3 January 2008 - Published in Atmos. Chem. Phys. Discuss.: 6 March 2008 \\ Revised: 22 July 2008 - Accepted: 24 July 2008 - Published: 19 August 2008
}

\begin{abstract}
An SUV-150B spectroradiometer for measuring solar ultraviolet (UV) irradiance was installed at Summit, Greenland, in August 2004. Here we compare the initial data from this new location with similar measurements from Barrow, Alaska, and South Pole. Measurements of irradiance at $345 \mathrm{~nm}$ performed at equivalent solar zenith angles (SZAs) are almost identical at Summit and South Pole. The good agreement can be explained with the similar location of the two sites on high-altitude ice caps with high surface albedo. Clouds attenuate irradiance at $345 \mathrm{~nm}$ at both sites by less than $6 \%$ on average, but can reduce irradiance at Barrow by more than $75 \%$. Clear-sky measurements at Barrow are smaller than at Summit by $14 \%$ in spring and $36 \%$ in summer, mostly due to differences in surface albedo and altitude. Comparisons with model calculations indicate that aerosols can reduce clear-sky irradiance at Summit by 4-6\%; aerosol influence is largest in April. Differences in total ozone at the three sites have a large influence on the UV Index. At South Pole, the UV Index is on average $20-80 \%$ larger during the ozone hole period than between January and March. At Summit, total ozone peaks in April and UV Indices in spring are on average 10-25\% smaller than in the summer. Maximum UV Indices ever observed at Summit, Barrow, and South Pole are 6.7, 5.0, and 4.0, respectively. The larger value at Summit is due to the site's lower latitude. For comparable SZAs, average UV Indices measured during October and November at South Pole are 1.9-2.4 times larger than measurements during March and April at Summit. Average UV Indices at Summit are over 50\% greater than at Barrow because of the larger cloud influence at Barrow.
\end{abstract}

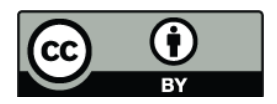

Correspondence to: G. Bernhard (bernhard@biospherical.com)

\section{Introduction}

Solar ultraviolet (UV) radiation reaching the Earth's surface has a wide range of effects on humans, and aquatic and terrestrial ecosystems (UNEP, 2003; ACIA, 2006). For humans, exposure to UV radiation has been linked to sunburn, skin cancer, corneal damage, and cataracts (de Gruijl et al., 2003). A beneficial effect of UV radiation is the photochemical production of Vitamin D in the skin (Lehmann, 2005). Vitamin $\mathrm{D}$ is essential for the formation of bones (Holick, 1996) and may also protect from internal cancers (Grant, 2002). The dichotomy formed from detrimental and beneficial UV effects is particularly noteworthy in the Arctic. On one hand, reflections from snow covered surfaces and the long hours of sunshine during summer months can lead to considerable UV exposure (Cockell et al., 2001). On the other hand, the virtual absence of UV-B radiation during winter months may result in Vitamin D deficiency (Webb et al., 1988; Engelsen et al., 2005) and associated diseases such as rickets (Stokstad, 2003).

Stratospheric ozone depletion and climate change (in particular changes in stratospheric temperatures, surface albedo, cloudiness and atmospheric circulation patterns) may modify the UV climate in the Arctic (Bernhard et al., 2007). Ozone decreases in the Arctic are less severe than in the Antarctic because of higher stratospheric temperatures in the North. Increased temperatures make the formation of polar stratospheric clouds (PSC) and the photochemical destruction of ozone less prevalent (WMO, 2007). However, in years when the polar vortex was strong and stratospheric temperatures remained cold (e.g., 1993, 1997, 2005), photochemically induced decreases in total ozone of up to $45 \%$ have been observed over localized areas of the Arctic (Fioletov et al., 1997; Newman et al., 1997). Stratospheric temperatures during the winter/spring season are currently often close to the threshold of PSC formation. Reductions of stratospheric temperatures as a consequence of climate

Published by Copernicus Publications on behalf of the European Geosciences Union. 
change, could increase the frequency of years with severe ozone depletion in the Arctic (Rex et al., 2004; WMO, 2007) and lead to marked increases in UV. Several studies have shown a longitudinal component of Arctic ozone concentrations, which have been explained by preferential locations of the Northern Polar Vortex, and by decadal variations in circulation patterns (Knudsen and Andersen, 2001; Andersen and Knudsen, 2006). It can therefore be assumed that changes of UV radiation will not be uniform across the Arctic.

Measurements of solar UV radiation in the Arctic are sparse despite the potentially large changes anticipated in the future (Taalas et al., 2000). Current monitoring efforts are limited to Alaska (Bernhard et al., 2007), Canada (Fioletov et al., 2001), Scandinavia (Lakkala et al., 2003), and Spitzbergen (Wuttke et al., 2005). There are no measurements in the vast region of the Russian Arctic. Here we report on first results from a new UV monitoring site, which was established in August 2004 at "Summit," located at the top of Greenland's ice cap. The instrument is now part of the US National Science Foundation's Ultraviolet Spectral Irradiance Monitoring Network (UVSIMN), operated by Biospherical Instruments Inc (BSI). Measurements from the new station were compared with data from the UVSIMN sites at the South Pole and Barrow, Alaska. South Pole was chosen as a reference site because it shares many commonalities with Summit such as location on a vast ice cap, high elevation, and high surface albedo. The main distinguishing factors between the two sites are their differences in stratospheric ozone concentrations and their geographical opposition. Barrow was chosen for comparison with an Arctic coastal location.

\section{Instrumentation and locations}

The instrument installed at Summit $\left(72^{\circ} 35^{\prime} \mathrm{N}, 38^{\circ} 27^{\prime} \mathrm{W}\right.$, $3202 \mathrm{~m}$ a.s.l.) is a SUV-150B spectroradiometer for measuring solar irradiance between 280 and $600 \mathrm{~nm}$. The instrument measures four spectra per hour. The SUV-150B is based on a $150 \mathrm{~mm}, \mathrm{f} / 4.4$ Czerny-Turner double monochromator, designed by BSI. The bandwidth is $0.63 \mathrm{~nm}$ full width at half maximum (FWHM). Wavelength stability of better than $\pm 0.02 \mathrm{~nm}( \pm 2 \sigma)$ is achieved by using high-resolution optical encoders for accurate position control of the monochromator's gratings. The instrument's irradiance collector consists of a polytetrafluoroethylene (PTFE) diffuser covering the entrance port of a baffled integrating sphere. The collector's cosine-error is $\pm 2 \%$ for incidence angles smaller than $75^{\circ}$. The instrument took part in the fifth North American Interagency Intercomparison for UV Spectroradiometers in 2003. Measurements of spectral irradiance in the UV-A agreed to within $5 \%$ with measurements of a reference spectroradiometer of the Network for the Detection of Stratospheric Change (NDSC). Differences at $300 \mathrm{~nm}$ were smaller than $8 \%$. More details on instrument specifications and results of the intercomparison campaign can be found in the work by Wuttke et al. (2006) and Network Operations Reports (e.g., Bernhard et al., 2006).

The instruments located at South Pole Station, Antarctica $\left(90^{\circ} \mathrm{S}, 2841 \mathrm{~m}\right.$ a.s.l.), and Barrow, Alaska $\left(71^{\circ} 19^{\prime} \mathrm{N}\right.$, $156^{\circ} 41^{\prime} \mathrm{W}, 8 \mathrm{~m}$ a.s.l.), are SUV-100 spectroradiometers (Booth et al., 1994), and were installed in 1988 and 1991, respectively. The instruments provide similar data products as the SUV-150B but have a larger bandwidth of $1.0 \mathrm{~nm}$ FWHM. Spectra were measured hourly until 1997 at both sites, and quarter-hourly thereafter.

South Pole Station (SPO) and Summit (SUM) are located on the top of vast ice caps with a surface albedo larger than 0.97 year-round. Barrow (BAR) is located at the coast of the Chukchi Sea, which is typically covered by ice between November and July. Snow cover extends roughly from October to June. The effective surface albedo is $0.83 \pm 0.08$ $( \pm 1 \sigma)$ during March and April and below 0.15 during $\mathrm{Au}-$ gust and September. Clouds are frequent in any month but have a greater optical depth in autumn than in spring. More information on data from SPO and BAR has been compiled by Bernhard et al. $(2004,2007)$.

Data from SUM presented here cover the period of August 2004-July 2007 (42 769 spectra). There is a gap between 18 May 2005 and 1 August 2005 when the system had to be removed for relocation of the host building. Data from SPO are from January 1991-January 2007 (182 495 spectra), and BAR data include January 1991-November 2006 (193026 spectra).

\section{Data analysis}

All data used in this study are "Version 2" NSF network data (Bernhard et al., 2004), which have been corrected for the instruments' wavelength and cosine errors, and adjusted for drifts of responsivity over time. All data are available via the website www.biospherical.com/NSF/Version2. Data products include full-resolution UV spectra, total ozone, effective albedo, and cloud optical depth. While the correction procedures are identical for all instruments, their magnitudes are different due to the different specifications of the SUV150B installed at SUM and the SUV-100 spectroradiometers operating at SPO and BAR. The maximum cosine correction of SUV-150B data in the UV is 3\% while the correction for SUV-100 data may be as large as $16 \%$. Corrections for wavelength errors are also smaller for the SUV-150B due to its advanced drive using optical encoders. SUV-150B measurements were initially affected by large changes in responsivity of up to $10 \%$ per month, however. These changes were mostly due to a rapid degradation ("yellowing") of the Barium-sulfate coating of the integrating sphere used in the instrument's original cosine collector. In response to the problem, the integrating sphere was replaced in August 2005 with one made from solid sections of PTFE. The replacement reduced the instrument's instability considerably to less than 


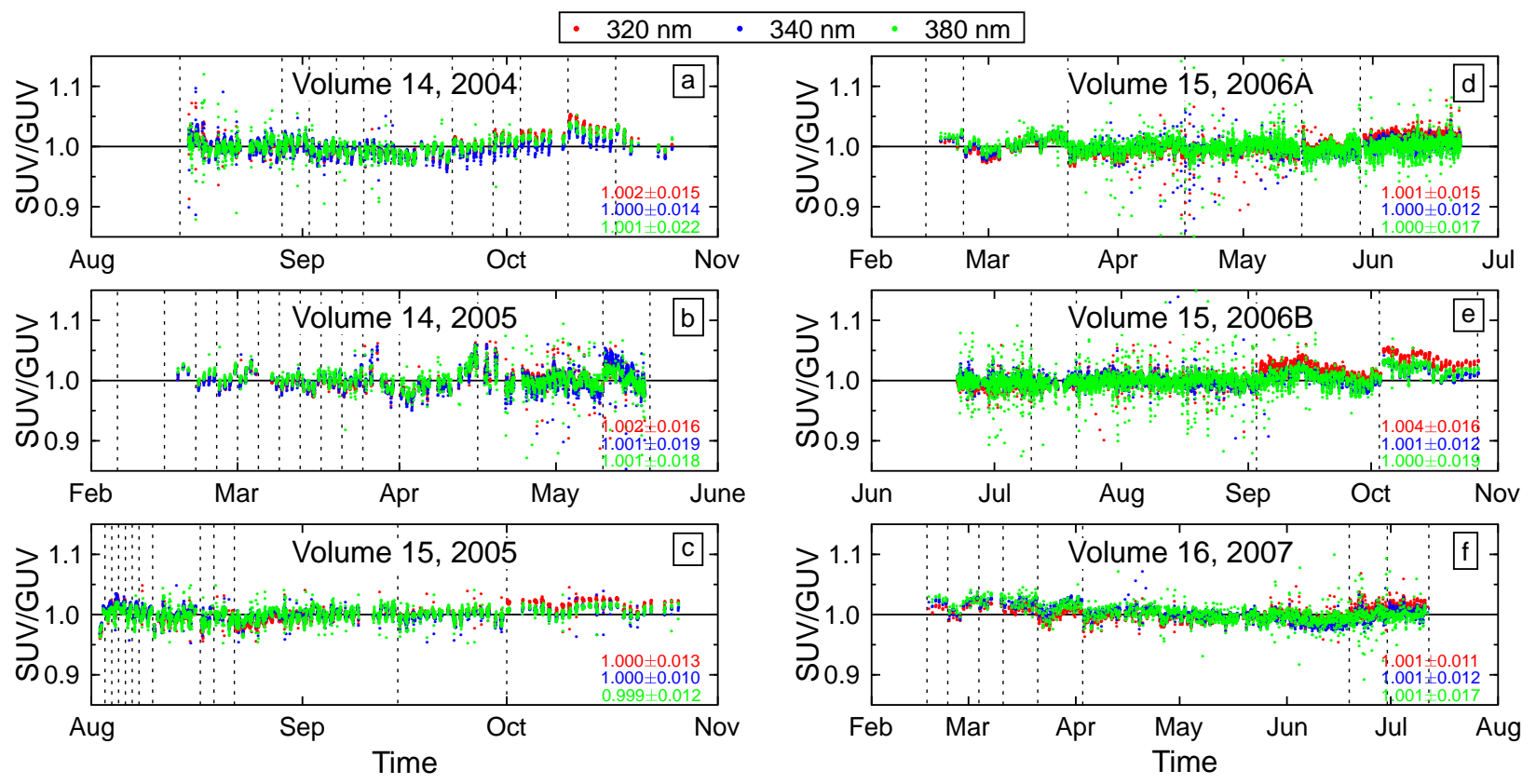

Fig. 1. Ratio of SUV-150B and GUV-511 measurements of spectral irradiance at 320,340, and $380 \mathrm{~nm}$ for six periods using data with solar zenith angles smaller than $85^{\circ}$. Vertical broken lines indicate times when the calibration of the SUV-150B was changed. (a) August 2004November 2004. (b) February 2005-June 2005. (c) August 2005-November 2005. (d) February 2006-July 2006. (e) June 2006-November 2006. (f) February 2007-August 2007. NSF UVSIMN data are organized in volumes. The volume of each period is indicated in the panels' headers. Average and standard deviation of ratios are indicated in the bottom right corner of every panel.

$2 \%$ per month. These drifts were monotonic and predictable over time, and could be corrected by linear interpolation of calibration scans, which were performed every two weeks.

To confirm that changes in responsivity have been adjusted appropriately, we compared SUV-150B data with measurements of a co-located GUV-511 multi-channel filter radiometer. For this comparison, SUV-150B spectra were weighted with the measured response functions of the GUV-511 as described by Bernhard et al. (2005). The analysis is complicated by the fact that the responsivity of the GUV-511 also changed over time. Between May 2004 and July 2007, the sensitivity of the GUV decreased monotonically by $19 \%$ at $320 \mathrm{~nm}, 7 \%$ at $340 \mathrm{~nm}$, and $10 \%$ at $380 \mathrm{~nm}$. To decouple the drifts of the two instruments, we calibrated the GUV511 radiometer against SUV-150B data using synchronous measurements collected during periods ranging from three to five months. Drifts of the GUV's 340 and $380 \mathrm{~nm}$ channels during these periods are smaller than $1.5 \%$. The method blends the strengths of both instruments: the responsivity of the SUV-150B is accurately known at the times of the biweekly calibrations, and the comparatively good short-term stability of the GUV-511 allows the assessment of changes in SUV-150B responsivity between calibration events.

Figure 1 shows the ratio of SUV-150B and GUV-511 measurements for 6 different periods. The ratios show discontinuities of up to $4 \%$ at times when the calibration of the SUV150B was changed, but the overall agreement is good: for solar zenith angle (SZA) smaller than $85^{\circ}$, standard deviations of the ratios of SUV/GUV range between 0.010 and 0.022 for all periods and wavelengths. The standard deviation calculated from all data points is 0.015 , confirming that responsivity changes of the SUV-150B have been corrected satisfactorily.

\section{Uncertainty budget}

Uncertainty budgets for data from the SUV-100 spectroradiometers at SPO and BAR have been published by Bernhard et al. (2004; 2007). Expanded uncertainties (coverage factor $k=2$, equivalent to uncertainties at the $2 \sigma$-level or a confidence interval of $95.45 \%$ ) for spectral irradiance at $345 \mathrm{~nm}$ and erythemal irradiance vary between $5.8 \%$ and $6.2 \%$. These are dominated by uncertainties related to the instruments' radiometric calibration, wavelength error, and cosine-error corrections. A detailed uncertainty budget for the SUV-150B at SUM is available at www.biospherical. com/nsf/Version2/Summit_info.asp. The expanded uncertainty is $6.0 \%$, and dominated by radiometric calibration and responsivity drift. The budgets for the two instrument types are very similar due to the large contributions from uncertainties related to the calibration standards (200-Watt tungstenhalogen lamps) used for all spectroradiometers. 

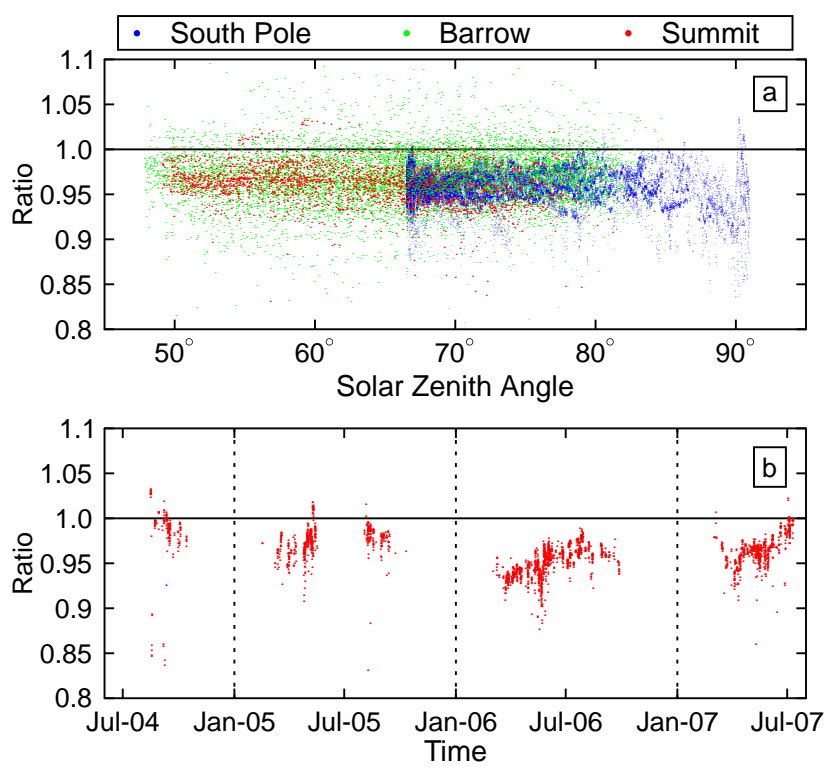

Fig. 2. Ratio of measured and modeled clear-sky spectra integrated over the wavelength range $342.5-347.5 \mathrm{~nm}$. (a) Ratio versus solar zenith angle for South Pole (blue), Barrow (green) and Summit (red). (b) Ratio versus time for Summit.

\section{Model calculations}

Measurements at all sites where complemented with calculations of the radiative transfer model UVSPEC/libRadtran Version 1.01 (Mayer and Kylling, 2005). The model's pseudospherical disort radiative transfer solver with six streams was used. These calculations are used for quality control, calculation of total ozone, and interpretation of differences seen in measurements at the three sites. Model calculations also provide reference clear-sky spectra. Model input parameters include: SZA; the extraterrestrial spectrum; atmospheric profiles of air density, temperature, ozone, and aerosol extinction; total column ozone; effective surface albedo; atmospheric pressure at station level; aerosol optical depth (parameterized by the Ångström coefficients $\alpha$ and $\beta$ ); and single scattering albedo for aerosols (SSA). Settings of these parameters for SPO and BAR are described by Bernhard et al. (2004, 2007). Ozone and temperature profiles for SUM were adopted from ozone sonde measurements performed at SUM by the Global Monitoring Division (GMD) of NOAA's Earth System Research Laboratory (ESRL). Total ozone was calculated from measured UV spectra according to the method by Bernhard et al. (2003), and compared with measurements of the Ozone Monitoring Instrument (OMI) on NASA's AURA platform. For SZAs smaller than $80^{\circ}$, the ratio of SUV-150B and OMI measurements is $1.010 \pm 0.019$ $( \pm 1 \sigma)$. Surface albedo was set to 0.97 in accordance with measurements by Grenfell and Warren (1994). Station pressure data were provided by NOAA. Aerosol optical depth is not being measured at Summit. Calculations were per- formed for stratospheric background aerosol conditions by setting $\alpha=1.0$ and $\beta=0.008$. This translates to an aerosol optical depth (AOD) of 0.016 at $500 \mathrm{~nm}$. Actual AODs are likely larger, in particular during spring when Summit may be affected by Arctic haze (Bodhaine and Dutton, 1993). Based on our analysis for BAR (Bernhard et al., 2007), we estimate that aerosols could reduce erythemal irradiance and irradiance at $345 \mathrm{~nm}$ on average by $4-5 \%$ in spring and $2-3 \%$ in summer. SSA was set to 0.99 .

Measurements during clear skies were compared with model results for all sites. Clear-sky periods were determined based on temporal variability of measured spectral irradiance at $600 \mathrm{~nm}$. The procedure is similar to that described by Bernhard et al. (2004) and is explained here in more detail. Spectral irradiance at $600 \mathrm{~nm}, E_{600}\left(t_{i}\right)$, was chosen as an indicator for cloud variability because longer wavelengths are more sensitive to clouds and less sensitive to surface albedo than wavelengths in the UV. $t_{i}$ indicates the time when spectrum $i$ was measured. Clear-sky periods were determined from a scatter plot of $E_{600}\left(t_{i}\right)$ versus solar zenith angle $\vartheta\left(t_{i}\right)$. Clear-sky data form a band of high point-density in this plot. A function $F$ of the type $F\left(\vartheta\left(t_{i}\right)\right)=a\left(\vartheta\left(t_{i}\right)-b\right)^{c}$ was fitted to this band, where $a, b$, and $c$ are fit-coefficients. Clear-sky spectra are determined by evaluating the expression $S\left(t_{i}\right)$, defined as:

$S\left(t_{i}\right)=\frac{E_{600}\left(t_{i}\right) / F\left(t_{i}\right)}{0.5\left[E_{600}\left(t_{i-1}\right) / F\left(t_{i-1}\right)+\left(E_{600}\left(t_{i+1}\right) / F\left(t_{i+1}\right)\right]\right.}-1$

The sky is considered clear-sky at time $t_{i}$ if the three conditions $\left|S\left(t_{i-1}\right)\right|<0.01,\left|S\left(t_{i}\right)\right|<0.01$, and $\left|S\left(t_{i+1}\right)\right|<0.01$ are met.

Figure 2a shows the ratio of irradiance measured during clear skies in the wavelength band $342.5-347.5 \mathrm{~nm}$ to the corresponding model result for all sites. Average ratios are $0.959 \pm 0.016( \pm 1 \sigma)$ for SPO, $0.969 \pm 0.030$ for BAR, and $0.967 \pm 0.024$ for SUM. The bias between measurement and model of about $3-4 \%$ is within the uncertainty of the measurements and model input parameters. For SPO and BAR, reasons for the discrepancy have been further analyzed by Bernhard et al. (2004, 2007). Data for SUM are also plotted versus time (Fig. 2b). Ratios for 2006 and 2007 show systematic increases from about 0.94 for early April to about 0.98 for July. This feature is mostly absent in data from 2005. The increases and the different pattern in data from 2005 compared to data from 2006 and 2007 cannot be explained with measurement errors alone and could be caused by differences in aerosol concentrations. The polar vortex of the winter 2004-2005 was the coldest on record, with strong chlorine activation from early January through early March 2005 (Manney et al., 2006). It also had a record-size vortex area in early March (Feng et al., 2007). Our analysis of GMD ozone profiles indicates that tropopause height (defined here as altitude of minimum temperature in GMD profiles) was approximately $8 \mathrm{~km}$ lower in 2005 compared to 2006 and 2007 for the period 14 March-22 April. The low tropopause 
height is indicative of a different weather pattern in 2005, which may have had an effect on the transport or aerosolrich air to SUM. A more quantitative assessment of aerosol effects is not possible due the lack of aerosol measurements at SUM and the gap in UV measurements between 18 May and 1 August 2005.

\section{Results}

\subsection{Total ozone}

Total ozone calculated from measured UV spectra is shown in Fig. 3 versus time (Fig. 3a) and SZA (Fig. 3b). There is a stark contrast between the annual cycles of total ozone at SPO and the two Northern-Hemisphere sites. At SPO, the lowest ozone columns are observed in the austral spring (October through early December), when Antarctica is affected by the ozone hole and total ozone is frequently below 220 DU. Total ozone at BAR and SUM is largest between February and April as a result of the Brewer-Dobson circulation (Holton et al., 1995). This phenomenon leads to a poleward transport of ozone from the tropics during the winter and early spring, causing an ozone maximum in spring and a minimum in autumn. During years when the stratosphere is cold enough for the extended formation of polar stratospheric clouds (PSC), substantial photochemical destruction of ozone can also be observed in the Northern Hemisphere (Rex et al., 2004). Such conditions occurred in the winter of 2004/2005 when the PSC area in January 2005 was the largest in 12 years (Feng et al., 2007). At SUM, the average total ozone column for the second half of February 2005 was $271 \mathrm{DU}$. This value is $30 \%$ below the longterm (1997-2004) average of 385 DU, which was calculated from measurements of the Total Ozone Mapping Spectrometer (TOMS) installed on NASA's Earth Probe (EP) satellite. A similarly strong depletion has not been observed at BAR.

Between July and October, total ozone amounts at BAR and SUM are comparable to ozone columns observed between mid-December and March at SPO. For July and August, monthly mean ozone columns at SUM and BAR are virtually identical. Monthly means for other months are considerably larger at BAR, which was also confirmed with TOMS/EP measurements of the years 1996-2005.

\subsection{UV radiation}

\subsubsection{Irradiance at $345 \mathrm{~nm}$}

Figure 4 shows measurements of spectral irradiance integrated over the range of $342.5-347.5 \mathrm{~nm}$ (hereinafter called "irradiance at $345 \mathrm{~nm}$ ") as a function of SZA for the three sites. Figures $4 \mathrm{a}$ and $\mathrm{c}$ are based on all available data; Figs. $4 \mathrm{~b}$ and $\mathrm{d}$ depict the clear-sky subset. The following can be concluded from results presented in Fig. 4:
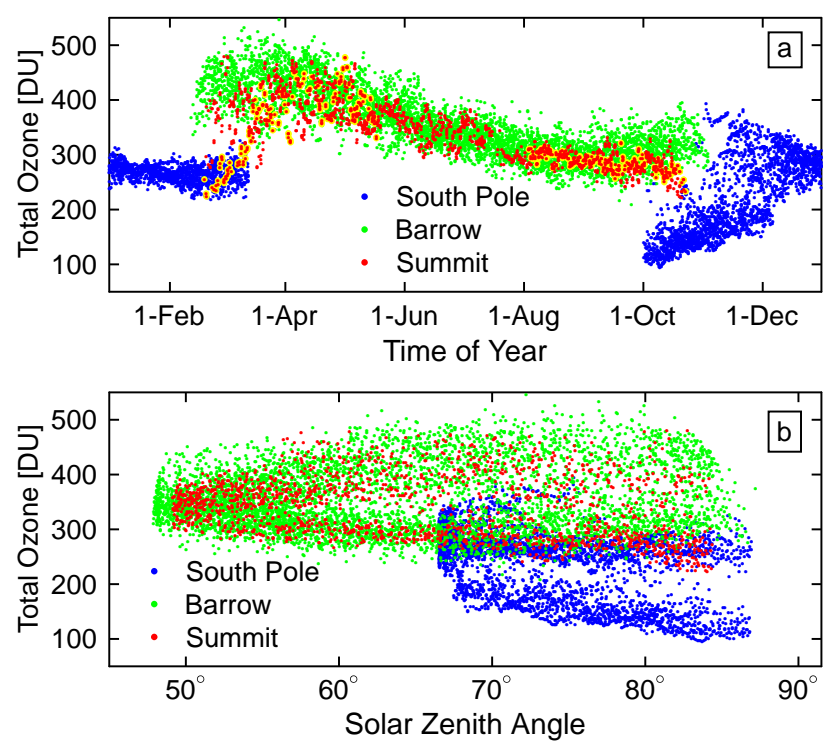

Fig. 3. Total ozone at Summit, South Pole and Barrow as a function of time of year (a) and solar zenith angle (b). Measurements at Summit from 2005 are highlighted in (a) by a yellow background.

- Measurements at SUM and SPO are very similar (Fig. 4a and b).

- The influence of clouds is very small at SPO and SUM (Fig. 4a) for two reasons: first, low temperatures over the ice caps lead to low atmospheric water content and optically thin clouds. By analyzing SUV-100 measurements in the visible, Bernhard et al. (2004) found that clouds at SPO have an optical depth of smaller than 1 in $71 \%$ of the time. This result is also quantitatively supported by data from longwave emission spectroscopy performed at SPO by Mahesh et al. (2001). Second, cloud attenuation is greatly moderated by high albedo due to multiple reflections between the snow-covered surface and clouds (Nichol et al., 2003).

- Measurements at BAR are substantially smaller than at SUM, mostly due to differences in cloudiness and surface albedo (Fig. 4c). The area of the highest pointdensity in the BAR data set is associated with clear-sky measurements during summer when albedo is low. Between 16 June and 30 September, clouds reduce irradiance at $345 \mathrm{~nm}$ by $33 \%$ on average; attenuation by more than $74 \%$ is observed for $5 \%$ of all spectra measured during this period. For more details see Bernhard et al. (2007).

- Clear-sky measurements at BAR are clustered into two groups (Fig. 4d). The upper group belongs to data measured roughly between February and April, when the albedo is $0.83 \pm 0.08$. The lower cluster is associated with clear-sky conditions during summer, when albedo is less than $5 \%$. 

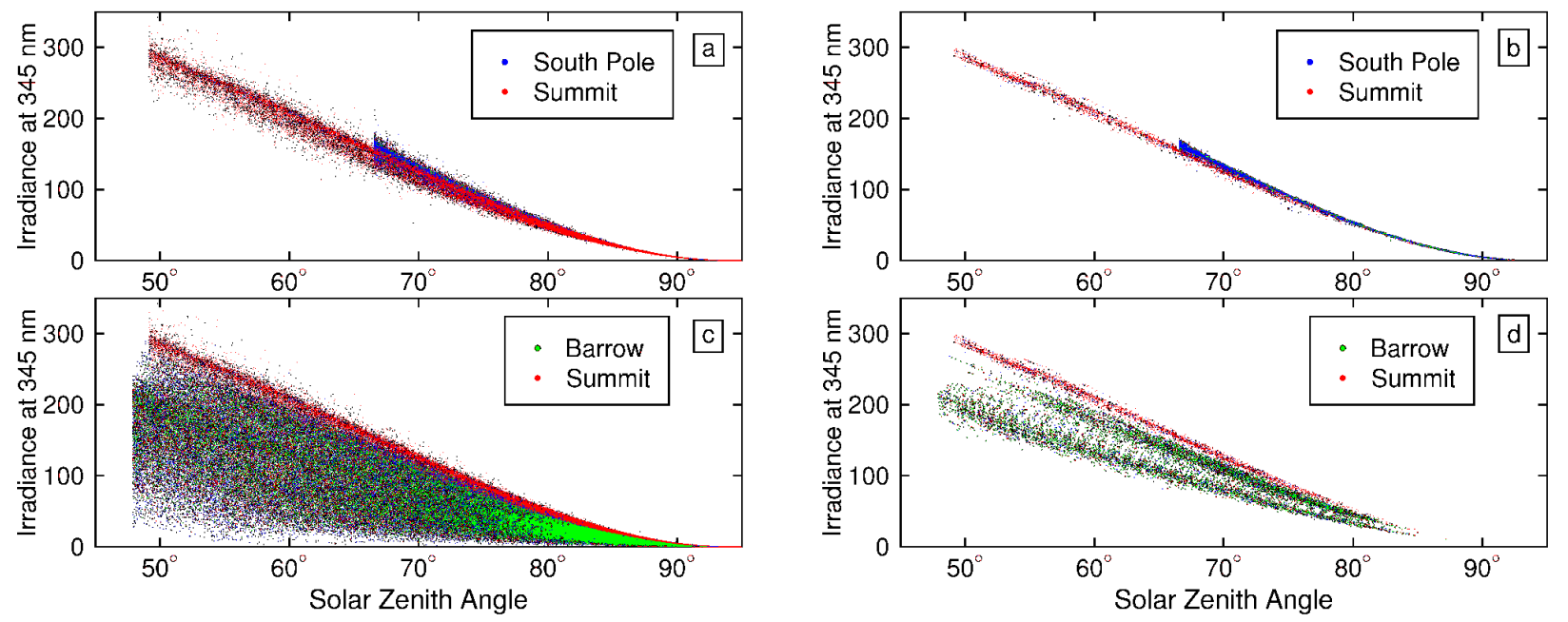

Fig. 4. Measurements of irradiance at $345 \mathrm{~nm}$ in units of $\mu \mathrm{W} / \mathrm{cm}^{2}$ at South Pole, Summit, and Barrow. (a) Comparison of all available data from South Pole and Summit. (b) Comparison of the clear-sky subsets for South Pole and Summit. (c) Comparison of all available data from Barrow and Summit. (d) Comparison of the clear-sky subsets for Barrow and Summit. Data from Summit shown in the upper and lower panels are identical.

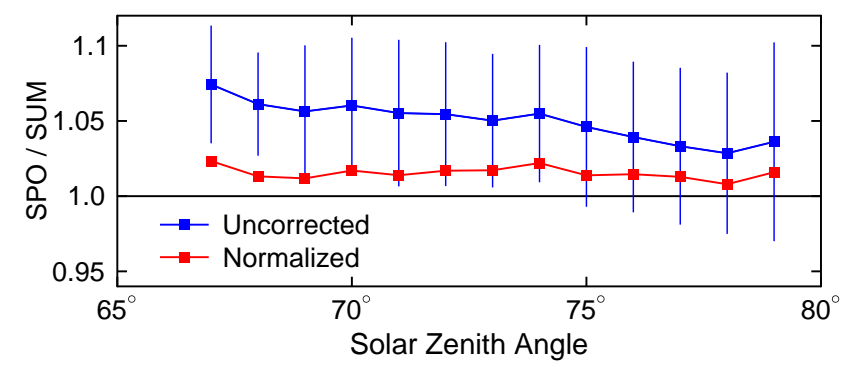

Fig. 5. Ratio of SPO/SUM irradiances at $345 \mathrm{~nm}$ measured during clear skies. Symbols indicate ratios $\bar{R}(\theta)=\bar{E}_{\mathrm{SPO}} / \bar{E}_{\mathrm{SUM}}$, where $\bar{E}_{\mathrm{SPO}}$ and $\bar{E}_{\mathrm{SUM}}$ are average irradiances measured in $1^{\circ}$-wide SZA-bins at SPO and SUM, respectively. Error bars were calculated as: $\bar{R}(\theta) \sqrt{\left(\sigma_{\mathrm{SPO}} / \bar{E}_{\mathrm{SPO}}\right)^{2}+\left(\sigma_{\mathrm{SUM}} / \bar{E}_{\mathrm{SUM}}\right)^{2}}$ where $\sigma_{\mathrm{SPO}}$ and $\sigma_{\mathrm{SUM}}$ are standard deviations of measurements in the SZA-bins at SPO and SUM. The blue data set represents the ratio of uncorrected measurements. The red data set is based on measurements normalized to an Earth-Sun distance of $1 \mathrm{AU}$.

The difference between SPO and SUM was examined in more detail by sorting all clear-sky measurements into $1^{\circ}$ wide SZA-bins, and forming the ratios of SPO/SUM. Results are shown in Fig. 5. Clear-sky measurements at SPO are larger than SUM data by $7 \%$ at $\mathrm{SZA}=67^{\circ}, 5 \%$ at $75^{\circ}$, and $4 \%$ at $79^{\circ}$, on average. This difference, and the small SZAdependence, can be explained almost entirely by the difference in Earth-Sun distance for the austral and boreal summer (Iqbal et al., 1983). When measurements of both sites are normalized to a Earth-Sun distance of 1 astronomical unit (AU), the ratio of SPO/SUM is 1.015 on average and does not exhibit any significant dependence on SZA (red data set in Fig. 5). This difference is well within the combined uncertainty budget of the two systems, although some contribution could possibly be due to the usually larger atmospheric aerosol loading at SUM.

The differences between BAR and SUM were analyzed in a similar way by binning clear-sky BAR data from the high and low albedo clusters shown in Fig. 4d, and comparing the results with the associated data from SUM. Results are shown in Fig. 6. For the period of high albedo (12 February to 30 April, designated as "spring"), measurements at BAR are on average $14 \pm 1 \%( \pm 1 \sigma)$ smaller than at SUM. For the period of low albedo (16 June to 30 September, designated as "summer"), measurements at BAR are on average $36 \pm 2 \%$ below values from SUM, indicating that the difference in albedo between spring and summer contributes about $22 \%$ to the difference. (If summer measurements at BAR had been used as the reference, spring measurements at BAR would have been higher by $38 \%$. This is consistent with the analysis presented by Bernhard et al., 2007. Measurements at SUM exceed summer measurements at BAR by about $56 \%$.)

The difference between measurements at SUM and BAR during spring are analyzed in more detail as follows. It can be assumed that some of the disparity stems from the differences in altitude ( $3202 \mathrm{~m}$ versus $8 \mathrm{~m}$ ) and albedo ( 0.97 versus $0.83 \pm 0.08)$. To quantify these effects, irradiance at $345 \mathrm{~nm}$ was modeled for each spectrum measured at BAR during clear skies based on the set of model input parameters described in Sect. 5. The results (denoted hereinafter "Run 1") were compared with modified calculations where the model parameters "altitude," "surface pressure," and "albedo" were set to $3202 \mathrm{~m}, 668 \mathrm{hPa}$, and 0.97 , respectively (Run 2). These 


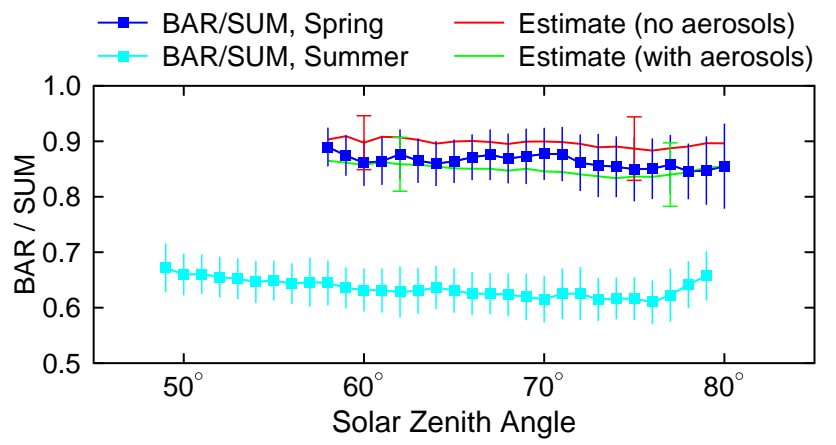

Fig. 6. Ratio of BAR/SUM irradiances at $345 \mathrm{~nm}$ measured during clear skies. Symbols indicate ratios $\bar{E}_{\mathrm{BAR}} / \bar{E}_{\mathrm{SUM}}$, where $\bar{E}_{\mathrm{BAR}}$ and $\bar{E}_{\text {SUM }}$ are average irradiances measured in $1^{\circ}$-wide SZA-bins at BAR and SUM, respectively. Ratios indicated by dark blue symbols are based on data measured between 12 February and 30 April when albedo at BAR is high. Light blue symbols indicate ratios from the period 15 June and 30 September when albedo at BAR is low. The red line shows the estimated ratio of BAR/SUM that can be expected from the differences in altitude and albedo of the two sites. The green line shows a similar estimate calculated from differences in altitude, albedo and aerosols, assuming background aerosols at SUM. Error bars were calculated in a similar way as those depicted in Fig. 5. Error bars for the estimated ratios are only shown for two SZAs for better clarity.

parameters represent typical conditions at Summit. The ratio of Run 1/Run 2 is a good estimate of the effect of the three parameters, and is plotted as a red line in Fig. 6. The ratio is approximately 0.89 , indicating that measurements at BAR should be $11 \%$ smaller than at SUM due to the differences in altitude and albedo. The disparity of about $3 \%$ between the modeled and measured ratio (blue line in Fig. 6) could be caused by differences in aerosol loading at the two sites. To investigate this assumption further, a third model run (Run 3) was executed by setting model aerosol parameters to background aerosol conditions $(\alpha=1.0$ and $\beta=0.008)$, and otherwise using the same modified parameters for altitude, pressure and albedo that were implemented for Run 2. Note that results shown in Fig. 2b suggests that SUM is also affected by aerosols, in particular during winter and early spring. Model calculations with background conditions are not intended to be a simulation for the actual aerosol loading at SUM (which is not known from measurements), but are instead an estimate of the maximum influence that can be expected from aerosol attenuation. The ratio of Run 1/Run 3 is plotted as a green line in Fig. 6 . The ratio is $4-6 \%$ below the ratio of Run 1/Run 2 discussed earlier, confirming results by Bernhard et al. (2007) that aerosols at BAR reduce irradiance at $345 \mathrm{~nm}$ by several percent. The measured ratio (blue line) is between the ratios of the model runs. This indicates that the actual aerosol attenuation at SUM is likely between the reductions expected for background conditions and the condition prevailing at BAR.

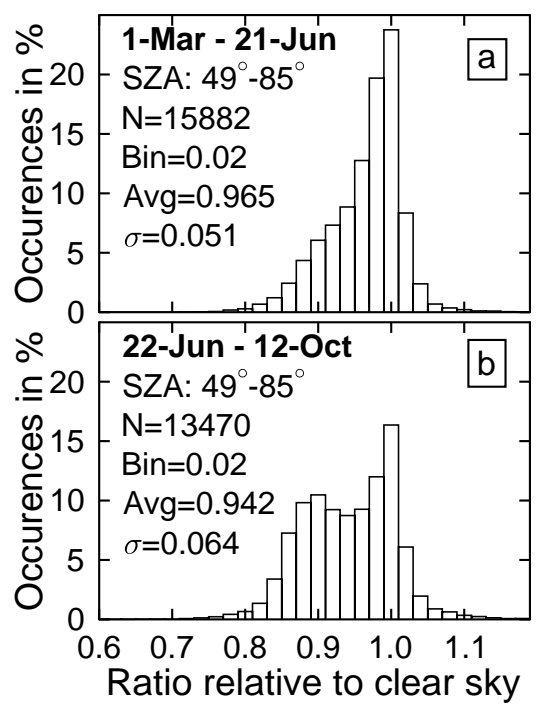

Fig. 7. Frequency distributions of transmittance $T$ defined as the ratio of spectral irradiance at $345 \mathrm{~nm}$ to clear sky irradiance. (a) Distribution for spring (1 March-21 June). (b) Distribution for summer (22 June-12 October). Both panels also indicate the SZA-range, number of data points $(N)$, width of the histogram columns (Bin), average (Avg), and standard deviation $(\sigma)$ of the distributions.

The effect of clouds on irradiance at $345 \mathrm{~nm}$ has been quantified for South Pole (Bernhard et al., 2004) and Barrow (Bernhard et al., 2007) in great detail. Here we present a similar analysis for Summit. The effect of clouds is described with frequency distributions of transmittance $T$, defined as the ratio of measured spectral irradiance at $345 \mathrm{~nm}$ to the associated clear sky irradiance value calculated with the model. Using the same method as applied by Bernhard et al. (2007), transmittances were corrected for the bias of 1 $6 \%$ between clear sky measurements and model values discussed earlier (e.g., Fig. 2). Transmittance values calculated from spectra measured at SZAs smaller than $85^{\circ}$ were selected from data of all years and binned into 0.02-wide intervals to set up two frequency distributions for spring and summer. Figure 7a shows the frequency distribution of $T$ for spring (defined here as period between 1 March and 21 June). Figure $7 \mathrm{~b}$ shows a similar distribution for summer (22 June12 October). Both distributions display a distinct maximum at $T(t)=1$, marking clear-sky conditions. The clear-sky peak is more pronounced in spring than summer, indicating that clouds are more frequent in the summer. The distribution for summer also shows a secondary maximum at 0.9 , which is an indication of extended periods of overcast conditions. The average transmittance is 0.965 for spring and 0.942 for summer. Attenuation by clouds by more than $17 \%(T(t)<0.83)$ is observed only for $1.2 \%$ of all cases in spring. The corresponding fraction for summer is $2.9 \%$. Enhancement of irradiance at $345 \mathrm{~nm}$ by clouds is less than $10 \%$, with few $(<0.5 \%)$ exceptions. 

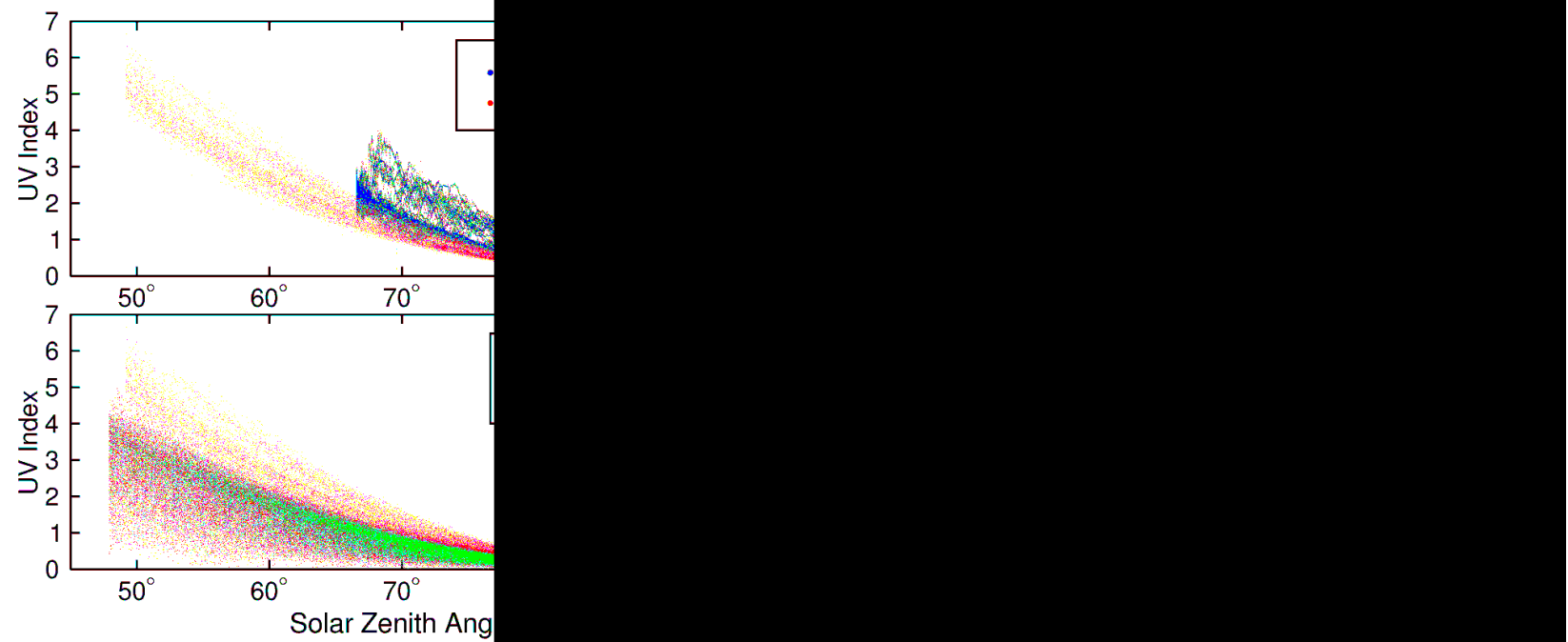

Fig. 8. Measurements of the UV Index at South Pole, Summit, and Barrow. (a) Comparison of all available data from South Pole and Summit. (b) Comparison of clear-sky subsets for South Pole and Summit. (c) Comparison of all available data from Barrow and Summit. (d) Comparison of the clear-sky subsets for Barrow and Summit. Data from Summit shown in the upper and lower panels are identical.

\subsubsection{UV Index}

Figure 8 shows measurements of the UV Index as a function of SZA for the three sites. The UV Index was calculated by weighting measured spectra with the CIE action spectrum for erythema (sunburn) (McKinlay and Diffey, 1987) and multiplying the result with $0.4 \mathrm{~cm}^{2} / \mu \mathrm{W}$ according to recommendations issued by WHO (2002). Measurements were again partitioned into all-sky (Fig. 8a and c) and clear-sky (Fig. 8b and d) cases. The following can be concluded:

- UV Indices are primarily controlled by the SZA.

- The overall maximum UV Indices are 6.7 at SUM, 5.0 at BAR and 4.0 at SPO. The maximum value for SUM is likely biased low due to the short data record for this site. To reduce this bias, we also calculated the 99th percentile of the UV Index measured within $3^{\circ}$ of the lowest SZA observed at the three sites. The resulting values are 6.2 at SUM, 4.4 at BAR and 3.5 at SPO.

- At SZA=70' UV Indices vary between 0.8 and 1.8 at SUM, 0.0 and 1.2 at BAR, and 1.0 and 3.4 at SPO. Average, median, 5th, and 95th percentiles at $\mathrm{SZA}=70^{\circ}$ are, respectively, 1.2, 1.2, 0.9, 1.6 for SUM; 0.7, 0.7, 0.3, 1.0 for BAR; and 1.9, 1.7, 1.2, 2.9 for SPO.

- For SZAs between $70^{\circ}$ and $75^{\circ}$, UV Indices measured at SPO during the period of the ozone hole exceed maximum indices observed at SUM by $50-60 \%$ on average. For SZAs between $77^{\circ}$ and $85^{\circ}$, the difference is about $75 \%$ (Fig. 8a and b). For times not affected by the ozone hole, measurements at SPO are comparable to maximum indices at SUM, but the majority of measurements at SUM are considerably below SPO levels.
- UV Indices at SUM exceed UV Indices at BAR by more than $50 \%$ on average (Fig. $8 \mathrm{c}$ and d).

- At SUM, the annual cycle in total ozone (Fig. 3) leads to a distinct seasonal UV Index variability. The lower halves of the ranges shown in Fig. $8 \mathrm{c}$ and d are mostly composed of measurements performed between February and May, whereas the upper halves are based on data collected between June and October (see also Fig. 9).

- Clear-sky UV Indices at BAR (Fig. 8d) are not clustered into two groups as was the case for irradiance at $345 \mathrm{~nm}$ (Fig. 4d). This is a consequence of the annual albedo and ozone cycles: enhancement of irradiance by larger albedo during February-April is balanced by the increased absorption by ozone during these months, leading to similar clear-sky UV Indices year-round for a given SZA. The relative importance of these two factors has been quantified in more detail by Bernhard et al. (2007).

The differences in UV Indices at the three sites were analyzed in more detail by dividing the measurements shown in Fig. 8a and c into spring and summer periods, and sorting the resulting datasets into to $1^{\circ}$-wide SZA-bins. Results are shown in Fig. 9a. For SZA $>68^{\circ}$, the largest UV Indices are observed at SPO during spring (15 September-30 November). There is little variability (indicated by errors bars) for SZAs larger than $80^{\circ}$ (19 October at SPO), because SPO is affected by the ozone hole nearly during all days of October. Considerably more variability is observed at smaller SZAs (November) due to large year-to-year changes in total ozone for this month (Fig. 3). UV Indices observed at SPO during summer (1 January-30 March) show also little variability. 
UV Indices at SUM are generally smaller than at SPO for comparable SZAs. Measurements at SUM during summer (15 June-30 September) exceed intensities in spring (15 February-30 April) because of larger ozone columns in the vernal months. One exception is the period of 15 February15 March of 2005 when total ozone was exceptionally small.

UV Indices at BAR are the smallest of the three sites. The difference in spring measurements between BAR and SUM is mostly due to the difference in albedo and altitude discussed earlier. Summer measurements at BAR are reduced due to small albedo and considerable cloud influence, leading to substantial variability in the UV Index as indicated by the large error bars in Fig. 9a.

To emphasize relative differences between the three sites at large SZAs, all data sets shown in Fig. 9a were ratioed against summer measurements at SUM, with results presented in Fig. 9b. The most striking feature is the large ratio for spring-time measurements at SPO. The ratio peaks at $\mathrm{SZA}=84^{\circ}$ (8 October at SPO), when measurements at SPO are factors of 2.3 and 5.0 larger than at SUM and BAR, respectively. The peak is a consequence of the small ozone column observed at SPO at this SZA (95 to 190 DU, depending on year). Despite the large relative difference in contrast to the two boreal sites, the average value of the UV Index on 8 October at SPO is only 0.4. The small value is again a manifestation of the large effect of SZA on UV radiation.

Ratios for the other data sets shown in Fig. 9b are 1.2-1.3 for "SPO summer;" $0.8-1.0$ for "SUM spring;" $0.6-0.8$ for "BAR spring;" and 0.4-0.5 for "BAR summer." Ratios for spring generally have a larger slope than those for summer as days with photochemically-induced spring-time ozone depletion typically occur early in the year and contribute mostly to bins with large SZA. One example of this effect is the period 15 February-15 March of 2005 when total ozone at SUM was below $350 \mathrm{DU}$. UV Indices from this period were binned and ratioed against summer measurements like the other data sets. The resulting ratios are indicated by a broken line in Fig. 9b. The period only contributes to bins with SZAs larger than $74^{\circ}$, and ratios are $20 \%$ on average larger than those of the "SUM spring" data set.

\subsubsection{Climatology of noontime measurements}

Table 1 provides a climatology of irradiance at $345 \mathrm{~nm}$ and the UV Index. The climatology is based on spectra measured close to local solar noon. The following times (provided in Universal Time) were associated with noon: Summit: 15:00; Barrow: 22:00; and South Pole: 00:00. These times were selected because spectra starting at these times are available for all years. To set up the climatology, average, median, 5th, and 95 th percentiles were calculated for every month from all available noontime measurements. At SUM, all four statistical parameters peak in June, both for irradiance at $345 \mathrm{~nm}$ and the UV Index. At BAR for irradiance at $345 \mathrm{~nm}$, the four parameters are highest in May. This shift of maximum values

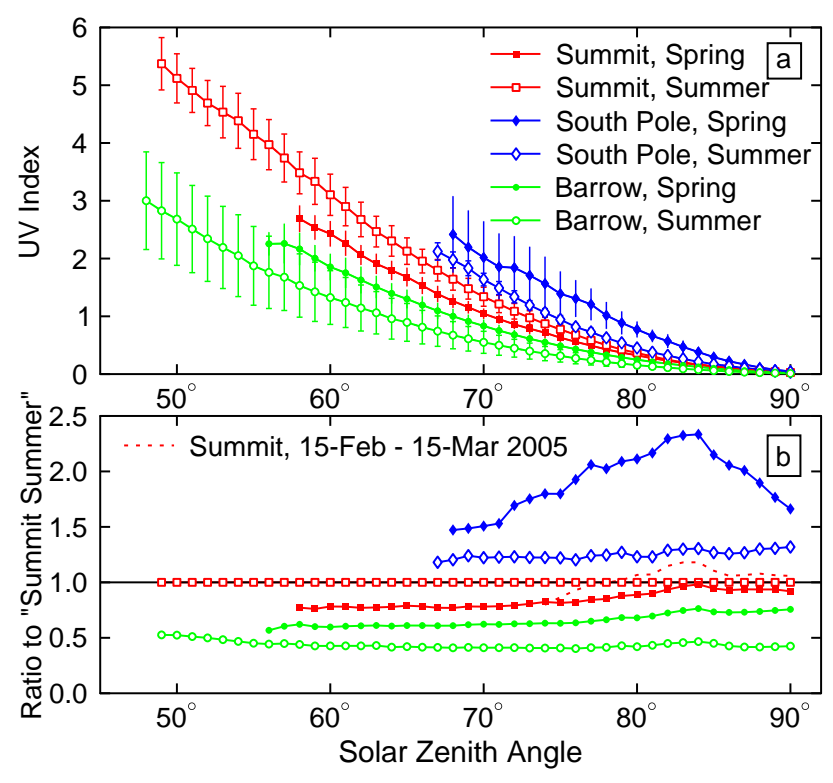

Fig. 9. Comparison of the UV Index at Summit, South Pole and Barrow. Data sets are divided into spring (15 September-30 November at SPO; 15 February-30 April at SUM and BAR) and summer (1 January-31 March at SPO; 15 June-30 September at SUM and BAR). No Earth-Sun distance correction was applied. (a) UV Index as a function of SZA. Symbols indicate the average UV Index in $1^{\circ}$-wide SZA-bins. Error bars indicate standard deviations of measurements in these bins. (b) Ratio of data sets presented in (a) against the "Summit Summer" data set. The data set indicated by a broken red line is based on Summit measurements from the period 14 February-15 March, 2005.

by one month towards spring is a consequence of the larger albedo and lower cloudiness in spring. The UV Index at BAR is also skewed toward the spring, although to a lesser extent than irradiance at $345 \mathrm{~nm}$. UV irradiances at SPO have their maximum in December but it is worth noting that the 95th percentile for the UV Index is almost identical for November and December. This is due to the low total ozone amounts in November, which almost offsets the larger SZA for this month.

\section{Conclusions}

Measurements from the UVSIMN network site at SUM were compared with similar measurements at SPO and BAR. Data were used for investigating the factors influencing solar UV radiation at high latitudes, and assessing differences in the UV climate between the Northern and Southern Hemisphere. When corrected for the difference in Earth-Sun distance, measurements of irradiance at $345 \mathrm{~nm}$ were almost identical at SUM and SPO. The influence of clouds is very small at the two sites due to low atmospheric water content and high surface albedo. For example, the average attenuation by clouds 
Table 1. Monthly climatology of noontime irradiance at $345 \mathrm{~nm}$ and the UV Index.

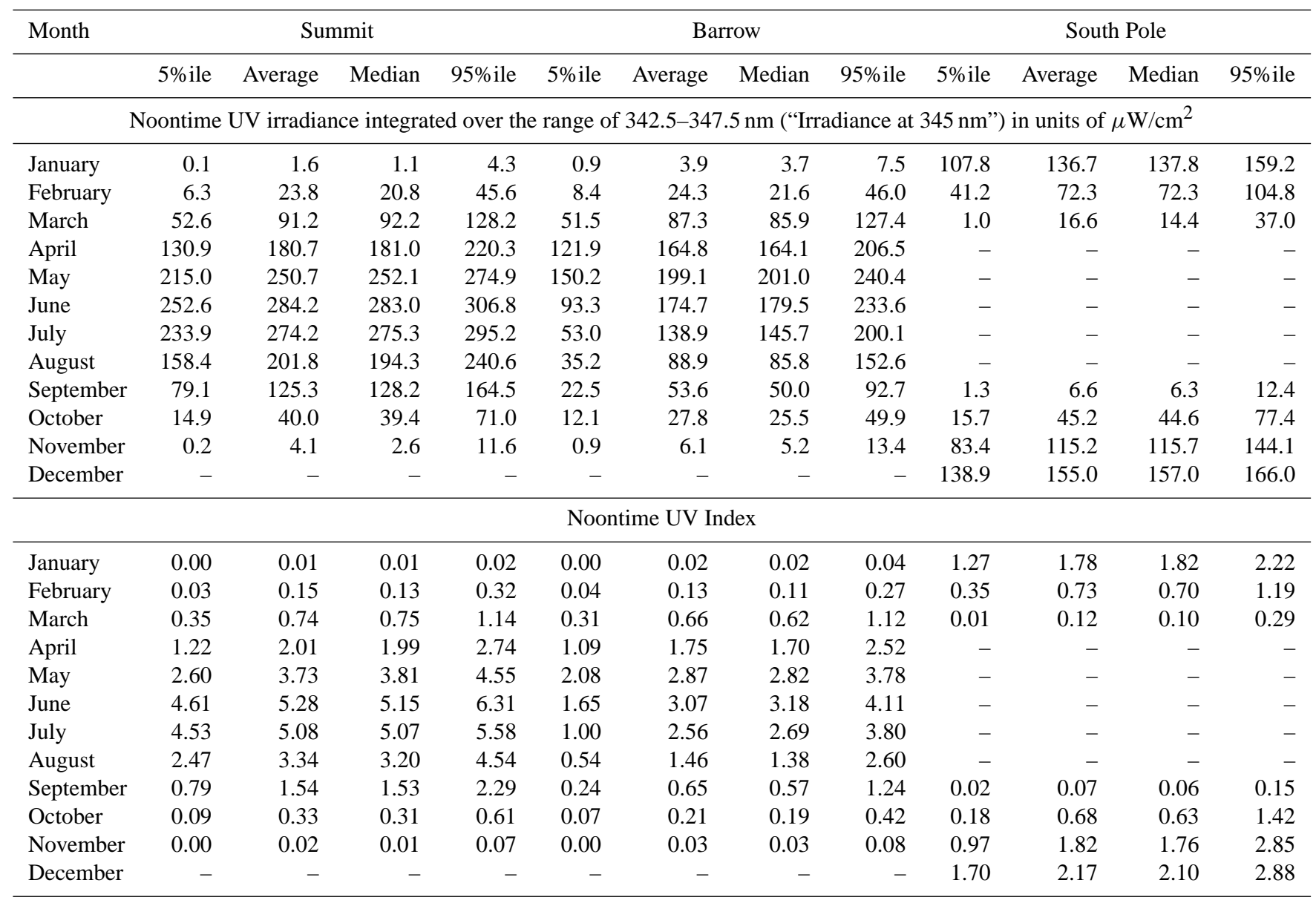

$5 \%$ ile denotes the 5 th percentile; $95 \%$ ile denotes the 95 th percentile

at SUM is $3.5 \%$ for spring and 5.8\% for summer. Clearsky measurements at BAR are substantially smaller than at SUM (i.e., $14 \%$ in spring and $36 \%$ in summer), mostly due to differences in surface albedo, altitude, and aerosols. Comparisons with model calculations have indicated that aerosols at BAR can reduce clear-sky irradiance at $345 \mathrm{~nm}$ by $4-6 \%$. The aerosol influence is largest in April and tapers off as the year progresses. This is consistent with the annual cycle of Arctic haze reported by Bodhaine and Dutton (1993). The aerosol signature was smaller in 2005 than in 2006 and 2007, possibly due to differences in meteorological conditions. Clouds at BAR can reduce irradiance at $345 \mathrm{~nm}$ by more than $75 \%$ during summer.

Differences in total ozone at the three sites have a large influence on the UV Index. At SPO, ozone columns are substantially reduced during the ozone hole period between September and November. UV Indices measured during these months are increased by $20-80 \%$ on average compared with measurements between January and March. The envi- ronment at SUM is quite the opposite. Total ozone peaks in April and UV Indices in spring are on average 10-25\% smaller than in the summer. One exception is the unusually cold winter of 2004/2005 (Feng et al., 2005), which led to large chemical ozone losses in February and March of 2005. This caused large relative enhancements of the UV Index at SUM. Absolute gains remained below 0.1 UV Index unit however, due to the low solar elevations prevailing during this period.

The maximum UV Index historically observed at SUM was 6.7, which exceeds the maximum UV Index at SPO by more than $50 \%$. This is mostly a consequence of SUM's lower latitude and larger solar elevations. For comparable SZAs, average UV Indices measured during October and November at SPO are 1.9-2.4 times larger than measurements during March and April at SUM. UV Indices at SUM exceed those at BAR by over $50 \%$, again mostly due to larger cloud influence at BAR. 
The conditions (e.g., albedo, altitude, aerosol influence, clouds) observed at SUM and SPO are representative for the Greenland ice cap and Antarctic plateau. We believe that results presented here can be generalized to other locations on the polar plains. Extrapolation to coastal areas is more problematic due to the influence of local effects, notably topography, inhomogeneous albedo, pollution, fog, and clouds as observed at BAR. Additional monitoring sites at high latitudes, particularly in Russia, would be required for a more complete assessment of the Arctic UV climate and long-term changes on a continental scale. For example, large parts of Siberia are influenced by the confluence of Atlantic and Pacific air masses and consequently are subject to a wide range of conditions spanning from pristine to polluted (Uttal et al., 2007). These circumstances provide a natural laboratory for assessing the effects of different aerosols, pollutants, and clouds on solar UV radiation. New knowledge can therefore be expected by measuring UV irradiance also in the Russian Arctic. We anticipate that continuance of measurements at SUM will prove helpful in assessing future changes of UV levels in Greenland, in particular with respect to changes in stratospheric temperatures, ozone (column and profile), aerosols, and atmospheric circulation patterns. To meet these objectives, it would be desirable if instruments for measuring aerosol properties, trace gas concentrations, and the radiation budget are established at SUM or any additional network sites that may be established in the future.

Additional comparisons of UV measurements at UVSIMN sites are currently being prepared and will be published in a book titled "UV Radiation in Global Change: Measurements, Modeling and Effects on Ecosystems." This publication will discuss noontime measurements and daily doses as function of Day of Year, and will complement results presented in this paper.

Acknowledgements. Operation of the UVSIMN and this study are funded by the National Science Foundation's Office of Polar Programs via a subcontract to Biospherical Instruments Inc from Raytheon Polar Services Company (RPSC). We are grateful to the many dedicated individuals who have operated SUV-150B and SUV-100 spectroradiometers at SUM, BAR, and SPO. We thank Bryan Johnson from NOAA/ESRL/GMD for providing ozone sonde measurements. Meteorological data from SUM were provided by Thomas Mefford from NOAA. OMI ozone data were acquired from the AURA Validation Data Center at http://avdc.gsfc.nasa.gov/. TOMS Earth Probe total ozone data were accessed via the website http://toms.gsfc.nasa.gov/. NOAA11 SBUV/2 profiles used for processing data at BAR were obtained from NOAA/NESDIS with support from the NOAA climate and global change program.

Edited by: M. Blumthaler

\section{References}

Andersen, S. B. and Knudsen, B. M.: The influence of polar vortex ozone depletion on $\mathrm{NH}$ mid-latitude ozone trends in spring, Atmos. Chem. Phys., 6, 2837-2845, 2006, http://www.atmos-chem-phys.net/6/2837/2006/.

Arctic Climate Impact Assessment (ACIA), Cambridge University Press, New York, USA, 1042 pp., 2005.

Bernhard, G., Booth, C. R., and McPeters, R. D.: Calculation of total column ozone from global UV spectra at high latitudes. J. Geophys. Res., 108(D17), 4532, doi:10.1029/2003JD003450, 2003.

Bernhard, G., Booth, C. R., and Ehramjian, J. C.: Version 2 data of the National Science Foundation's Ultraviolet Radiation Monitoring Network - South Pole, J. Geophys. Res., 109, D21207, doi:10.1029/2004JD004937, 2004.

Bernhard, G., Booth, C. R., and Ehramjian, J. C.: Real-time ultraviolet and column ozone from multichannel ultraviolet radiometers deployed in the National Science Foundation's ultraviolet monitoring network, Optical Engineering, 44(4), 041011-1-04101112,2005

Bernhard, G., Booth, C. R., Ehramjian, J. C., and Quang, V. V.: NSF Polar Programs UV Spectroradiometer Network 2004-2005, Operations Report Volume 14.0, Biospherical Instruments Inc., San Diego, USA, available at: www.biospherical.com/NSF, 2006.

Bernhard, G., Booth, C. R., Ehramjian, J. C., Stone, R., and Dutton, E. G.: Ultraviolet and visible radiation at Barrow, Alaska: Climatology and influencing factors on the basis of version 2, National Science Foundation network data, J. Geophys. Res., 112, D09101, doi:10.1029/2006JD007865, 2007.

Bodhaine, B. A. and Dutton, E. G.: A long-term decrease in Artic haze at Barrow, Alaska, Geophys. Res. Lett., 20, 947-950, 1993.

Booth, C. R., Lucas, T. B., Morrow, J. H., Weiler, C. S., and Penhale, P. A.: The United States National Science Foundation's polar network for monitoring ultraviolet radiation, in: Ultraviolet Radiation in Antarctica: Measurement and Biological Effects, Antarct. Res. Ser., 62, edited by: Weiler, C. S. and Penhale, P. A., AGU, Washington D.C., USA, 17-37, 1994.

Cockell, C. S., Scherer, K., Horneck, G., Rettberg, P., Facius, R., Gugg-Helminger, A., Driscoll, C., and Lee, P.: Exposure of Arctic field scientists to ultraviolet radiation evaluated using personal dosimeters, Photochem. Photobiol., 74(4), 570-578, 2001.

de Gruijl, F. R., Longstreth, J., Norval, M., Cullen, A. P., Slaper, H., Kripke, M. L., Takizawag, Y., and van der Leun, J. C.: Health effects from stratospheric ozone depletion and interactions with climate change, Photochem. Photobiol. Sci., 2, 16-28, 2003.

Engelsen, O., Brustad, M., Aksnes, L., and Lund, E.: Daily duration of vitamin D synthesis in human skin with relation to latitude, total ozone, altitude, ground cover, aerosols and cloud thickness, Photochem. Photobiol., 81, 1287-1290, 2005.

Feng, W., Chipperfield, M. P., Davies, S., von der Gathen, P., Kyrö, E., Volk, C. M., Ulanovsky, A., and Belyaev, G.: Large chemical ozone loss in 2004/2005 Arctic winter/spring, Geophys. Res. Lett., 34, L09803, doi:10.1029/2006GL029098, 2007.

Fioletov, V. E., Kerr, J. B., Wardle, D. I., Davies, J., Hare, E. W., McElroy, C. T., and Tarasick, D. W.: Long-term ozone decline over the Canadian Arctic to early 1997 from ground-based and balloon observations, Geophys. Res. Lett., 24(22), 2705-2708, 1997. 
Fioletov, V. E., McArthur, L. J. B., Kerr, J. B., and Wardle, D. I.: Long-term variations of UV-B irradiance over Canada estimated from Brewer observations and derived from ozone and pyranometer measurements, J. Geophys. Res., 106(D19), 23009 $23028,2001$.

Grant, W. B.: An estimate of premature cancer mortality in the US due to inadequate doses of solar ultraviolet-B radiation, Cancer, 94(6), 1867-1875, 2002.

Grenfell, T. C., Warren, S. G., and Mullen, P. C.: Reflection of solar radiation by the Antarctic snow surface at ultraviolet, visible, and near infrared wavelengths, J. Geophys. Res., 99(D9), 18 669-18 684, 1994.

Holick, M.: Vitamin D and Bone Health, J. Nutr., 126, 1159S1164S, 1996.

Holton, J. R., Haynes, P. H., McIntyre, M. E., Douglass, A. R., Rood, R. B., and Pfister, L.: Stratosphere-troposphere exchange, Rev. Geophys., 33(4), 403-440, 1995.

Iqbal, M.: An introduction to solar radiation, Academic Press, New York, USA, 390 pp., 1983.

Knudsen, B. M. and Andersen, S. B.: Longitudinal variation in springtime ozone trends, Nature, 413, 699-700, 2001.

Lakkala, K., Kyrö, E., and Turunen, T.: Spectral UV measurements at Sodankylä during 1990-2001, J. Geophys. Res., 108(D19), 4621, doi:10.1029/2002JD003300, 2003.

Lehmann, B.: The vitamin D3 pathway in human skin and its role for regulation of biological processes, Photochem Photobiol., 81(6), 1246-1251, 2005.

Mahesh, A., Walden, V. P., and Warren, S. G.: Ground-based infrared remote sensing of cloud properties over the Antarctic plateau - Part 2: Cloud optical depths and particle sizes, J. Appl. Meteorol., 40, 1279-1294, 2001.

Manney, G. L., Santee, M. L., Froidevaux, L., Hoppel, K., Livesey, N. J., and Waters, J. W.: EOS MLS observations of ozone loss in the 2004-2005 Arctic winter, Geophys. Res. Lett., 33, L04802, doi:10.1029/2005GL024494, 2006.

Mayer, B. and Kylling, A.: Technical note: The libRadtran software package for radiative transfer calculations - description and examples of use, Atmos. Chem. Phys., 5, 1855-1877, 2005, http://www.atmos-chem-phys.net/5/1855/2005/.

McKinlay, A. F. and Diffey, B. L.: A reference action spectrum for ultraviolet induced erythema in human skin, in: Commission International de l'Éclairage (CIE), Research Note, 6(1), 17-22, 1987.
Newman, P. A., Gleason, J. F., McPeters, R. D., and Stolarski, R. S.: Anomalously low ozone over the Arctic, Geophys. Res. Lett., 24(22), 2689-2692, 1997.

Nichol, S. E., Pfister, G., Bodeker, G. E., McKenzie, R. L., Wood, S. W., and Bernhard, G.: Moderation of cloud reduction of UV in the Antarctic due to high surface albedo, J. Appl. Meteorol., 42(8), 1174-1183, 2003.

Rex, M., Salawitch, R. J., von der Gathen, P., Harris, N. R. P., Chipperfield, M. P., and Naujokat, B.: Arctic ozone loss and climate change, Geophys. Res. Lett., 31, L04116, doi:10.1029/2003GL018844, 2004.

Stokstad, E.: Nutrition: the vitamin D deficit, Science, 302, 18861888, 2003.

Taalas, P., Kaurola, J., Kylling, A., Shindell, D., Sausen, R., Dameris, M., Grewe, V., Herman, J., Damski, J., and Steil B.: The impact of greenhouse gases and halogenated species on future solar UV radiation doses, Geophys. Res. Lett., 27(8), 11271130, 2000.

United Nations Environmental Program (UNEP): Environmental effects of ozone depletion and its interactions with climate change: 2002 assessment; executive summary, Photochem. Photobiol. Sci., 2, 1-4, 2003.

Uttal, T., Makshtas, A., Paatero, J., Hansen, G., and Intrieri, J.: A new climate observatory facility in Tiksi, Russia, Geophys. Res. Abstr., 9, 11193, 2007.

Webb, A. R., Kline, L., and Holick, M. F.: Influence of season and latitude on the cutaneous synthesis of vitamin D3: exposure to winter sunlight in Boston and Edmonton will not promote vitamin D3 synthesis in human skin, J. Clin. Endocrinol. Metab., 67(2), 373-378, 1988.

World Health Organization (WHO): Global Solar UV Index: A Practical Guide, Geneva, Switzerland, available at: http://www. unep.org/PDF/Solar_Index_Guide.pdf, 2002.

World Meteorology Organisation (WMO): Scientific assessment of ozone depletion: 2006, Global Ozone Res. Monit. Proj., Rep. 50, Geneva, Switzerland, 2007.

Wuttke, S., Schrems, O., Seckmeyer, G., and Hanken, T.: Spectral measurement of UV irradiance in polar Regions, European Geosciences Union, Geophys. Res. Abstr., 7, 08419, 2005.

Wuttke, S., Seckmeyer, G., Bernhard, G., Ehramjian, J., McKenzie, R., Johnston, P., and O’Neil, M.: New spectroradiometers complying with the NDSC standards, J. Atmos. Ocean. Technol., 23(2), 241-251, 2006. 